\title{
Las discursividades del arte: un lugar para el dislocamiento de los dispositivos escolares*
}
Revista Colombian
Investigaciones de Educación, N. 63.
Segundo semestre de 2012
Bogotá, Colombia.

\section{//The discursiveness of the art: A place for the displacement of school devices \\ //As discursividades da arte: um lugar \\ para o deslocamento de dispositivos escolares}

\section{Claudia Mallarino Flórez**}

Recibido:10/06/2012 Evaluado:26/09/2012

\begin{abstract}
* Este texto hace referencia a la investigación: "Efectos [resistencia / sujeción] del funcionamiento de dispositivos y racionalidades acerca del cuerpo joven en la escuela hoy [lugar / motivo]", que está siendo desarrollada actualmente en el marco del Doctorado Interinstitucional en Educación de la Universidad Pedagógica Nacional y la Universidad del Valle. Licenciada en Educación Física, Especialista en Didáctica y Pedagogía de la Educación Física y Magíster en Docencia Universitaria, de la Universidad Pedagógica Nacional, con estudios pre-doctorales en Metódica y Episteme: Indagación Crítica y Creación con el Instituto IPECAL de México. Es diplomada en Desarrollo del Potencial de Aprendizaje y del Pensamiento Divergente por el Proyecto CISNE de Investigación lo que acredita su formación en procesos de mediación fundamentados en Modificabilidad Estructural Cognitiva. Es doctorando del Doctorado Interinstitucional en Educación - UPN/UNIVALLE. Actualmente trabaja como profesora invitada y asesora en la Universidad de San Buenaventura - Cali, con el Convenio Mincultura-IPC en el programa de "Fortalecimiento de procesos formativos en danza: gestión corporal y gestión curricular" y con la OEI - Organización de Estados Iberoamericanos para la Educación la Ciencia y la Cultura en la estructuración de una escuela de formación actoral para la Fundación Arte \& Friends. Correo electrónico: cmallarino@yahoo.es
\end{abstract}

\section{Resumen}

La escuela moderna posee formas singulares y específicas de discursividad acerca del cuerpo, que han constituido dispositivos, delimitados desde instancias propias del poder -campos de fuerza- y desde instancias propias del saber -racionalidades-. Estos dispositivos, determinados históricamente, han naturalizado prácticas corporales de sujeción o de resistencia, según se han jugado estratégicamente en ámbitos de expresión de la corporalidad. Racionalidades analógicas propias de los lenguajes artísticos parecen emerger como condición de posibilidad de una corporalidad genuina y completa.

\section{Abstract}

The modern school has singular and specific forms of discourse about the body that constitute devices that are defined by instances proper to power power fields - and by instances proper to knowledge - rationalities. These historically determined devices have naturalized corporal practices of subjection and/or resistance depending on the way in which they have been strategically deployed in areas of corporal expression. In this scenario, analogical rationalities proper to artistic languages would seem to emerge as a condition for the possibility of a genuine and complete corporality.

\section{Resumo}

A escola moderna possui formas singulares e específicas de discursividade sobre o corpo que tem constituído dispositivos delimitados a partir de instâncias próprias do poder - campos de força - e a partir de instâncias próprias do saber - racionalidades. Esses dispositivos, determinados historicamente, tem naturalizado práticas corporais de sujeição e/ou de resistência, conforme tenham sido jogados estrategicamente em âmbitos de expressão da corporalidade. Racionalidades analógicas próprias das linguagens artísticas parecem emergir como condição de possibilidade de uma corporalidade genuína e complexa.

\section{Palabras Clave}

Cuerpo, escuela, dispositivo, sujeción/resistencia, arte.

\section{Keywords}

Body, school, device, subjection/resistance, art.

\section{Palavras chave}

Corpo, escola, dispositivo, sujeição/resistência e arte. 


\section{La apuesta}

Las discursividades son enunciaciones sujetas a condiciones de posibilidad del saber acerca de algo, que delimitan sus funciones merced al acto mismo de enunciar. La circunstancia de acceder a la posibilidad de ser enunciado sugiere que hay un poder del saber implícito y materializado en ámbitos que suelen ser contradictorios, de luchas y enfrentamientos y de fuerzas propias de los juegos estratégicos del saber/poder. Estas discursividades dan cuenta de la unidad y la diversidad humanas, de identidades singulares y plurales, y promueven o desdibujan versiones de mundo, pues a diferencia de todo lo demás, "el hombre al existir tiene que hacerse su existencia" (Ortega y Gasset, 1983, p. 341). Las discursividades, como enunciados de lo posible, están constituidas y son constitutivas de lo que existe y de lo que está por hacerse; por esta razón, determinan lo que se puede y no se puede decir, lo admitido y lo prohibido, lo que se aprueba y se desaprueba y lo que se dice sotto voce, pero que termina siendo un secreto a voces porque determina la propia existencia de quien lo enuncia.

Las discursividades de las que hablamos están fechadas y situadas y van a darse dentro de regímenes específicos de saber/poder en la escuela moderna y a propósito de un asunto en particular: los saberes acerca del cuerpo. La racionalidad, más que un saber, es una voluntad de saber, en tanto su saber es producto de una actitud ilustrada propia de la modernidad, pero lejos de tener garantizada su verdad, se irá enredando en las lógicas de un campo estratégico de fuerzas, distante y extraño en donde queda atrapado el sujeto, inmerso en juegos móviles y desiguales que actúan al margen de esa voluntad de saber ${ }^{1}$, siguiendo sus propias lógicas, las lógicas del poder. Esta condición de distancia del saber/poder que preside lo legítimo/ ilegítimo y lo central/periférico es contexto propicio para el ejercicio de los llamados dispositivos: "se trata de pensar al sexo sin la ley y al poder sin el rey" (Foucault, 1998, p. 54)².

\footnotetext{
Se hace referencia al complemento del título que da Foucault a su Historia de la sexualidad I, pues allí como aquí el saber se trata dentro de los cánones particulares de la modernidad, caracterizada por esa "voluntad de saber". http://www.uruguaypiensa. org.uy/imgnoticias/681.pdf

2 Foucault termina su capítulo de "La apuesta" en Historia de la sexualidad" con esta frase magistral para introducir el capítulo del "Método", donde despliega su mirada acerca del poder.
} 
[...] hay que ser nominalista, sin duda: el poder no es una institución, y no es una estructura, no es cierta potencia de la que algunos estarían dotados: es el nombre que se presta a una situación estratégica compleja en una sociedad dada" ${ }^{\prime 3}$.

Así entonces, el saber/poder se juega en una pugna constante de fuerzas enmascaradas entre sujetados y resistentes, pues el poder que sujeta le garantiza al poder que resiste, el material desde el cual este último actúa. Resistencia sin sujeción y sujeción sin resistencia, quedarían vacías de puntos de engranaje desde los cuales desplegar sus fuerzas transformadoras.

\section{Dispositivos escolares}

La escuela moderna está constituida por dispositivos: campos de fuerza y racionalidades, externos a ella, pues obedecen a sistemas de poder que regulan sus prácticas y sus discursos (Estado, empresa, capitalismo, globalización, Iglesia) desde líneas de acción estratégicas y políticas concretas [biopolíticas, anatomopolíticas, neoliberalismo, etc.); y a sistemas de saber a través de los cuales se materializan estas estrategias y políticas (ley, ciencia,

3 Esta frase de Foucault la usa Antonio Rodríguez Jaramillo como epígrafe de su texto El poder: una circunstancia en el pensamiento de Foucault. mercado, tecnología, religión, pedagogías de la sexualidad, etc.).

Todos estos elementos han determinado la escuela a partir de la segunda mitad del siglo XX, en cuanto ella, como experiencia histórica de la modernidad, ha sido matriz de incorporación del andamiaje de la productividad al mundo educativo y escenario de las exigencias de una nueva economía mundial; pero también, estos regímenes la configuran desde dentro como ejes de gravitación de un saber sobre el poder (instancias directivas y administrativas); $y$ de un poder de saber (instancias académicas, científicas e intelectuales); que han constituido las discursividades que fundamentan, fomentan y definen sus contextos y su acción sobre los individuos.

Si bien la educación poseía una estructura articulada y una organización que desde mediados del siglo XIX respondía a una cierta secuencia [...] al asumirse como sistema educativo, [la educación] ingresó en el ámbito de la planificación y del control, ejes fundamentales de la modernización social y económica (Martínez, 2004, p. 51).

Lo anterior determina que estos dispositivos sean de naturalezas distintas: a) endógenos, propios de lo educativo institucionalizado que se 
nombra desde discursividades autorizadas y no autorizadas pero inherentes a la escuela, y que obedecen a conceptos y categorías formalizados por ella -pedagogía, didáctica, currículo oculto, docente, estudiante, evaluación, plan-, y b) exógenos, propios de otras instancias que la determinan desde lógicas externas a su jurisdicción inmediata -economía, política, productividad, trabajo, capital-. Así mismo, estos regímenes configuran a la escuela como lugar y como motivo de producción de un saber/ poder acerca del cuerpo. Como lugar, pues es ahí, no en otra parte, donde se deben dar ciertas prácticas que la sociedad ha delimitado para ella: “¿Qué lugar se atribuye la pedagogía en lo referente a la existencia de un niño carente, necesitado e incompleto? [...] ¿Cómo el discurso pedagógico se hace cargo y a la vez construye esa transformación?" (Narodowski, 1999, p. 33); y como motivo, pues es este momento en la vida de las personas y no otro, el propicio para instalar y naturalizar prácticas a través de las cuales se expresan las diferentes instancias en las que se va a desarrollar su vida futura:

[...] la infancia supone mayor capacidad para aprender porque nada hay todavía aprendido. Terreno monopolítico de la simplicidad, los primeros años en la vida de un hombre son determinantes en la serie de aprendizajes a lograr ya que no hay aprendizajes aún. Ámbito privativo del adquirir, la niñez no puede ser otra cosa que el inicio $y$, por ende, la base para el logro de metas superiores. El recorrido posee un final pretendido constituido por la completitud, por lo que se infiere que, seguramente halla un único inicio posible: la falta y, recíprocamente, la capacidad. (Narodowski, 1999, p. 48).

Durante la segunda mitad del siglo $\mathrm{XX}$, la escuela se vio captada por nuevas teorías y demandas sociales, $y$ ha sido lugar $y$ motivo de modos diversos de modernización: "[...] el paso de la escuela expansiva a la escuela competitiva señala dos formas de modernización de la escuela y no una nueva educación en una sociedad nueva" (Martínez, 2004, p. 12). La primera forma que se enuncia como escuela expansiva estaría caracterizada por la consolidación de los sistemas de educación de masas gracias al desbloqueo de la escolarización y la asunción de la educación como pieza clave para el desarrollo y la construcción de un futuro para todos. La educación se vuelve prioridad y garantía de la equidad social así como agenda básica del siglo XXI, para lo 
cual se fundan programas como el Programa de las Naciones Unidas para el Desarrollo (PNUD), entre muchos otros. La inclusión y la cobertura determinan la adopción de sistemas educativos institucionalizados y homogéneos, que garanticen el acceso al conocimiento en un grado suficiente, y que le permitan al país entrar en el concierto competitivo nacional e internacional, expandiendo su economía a la vez que desdibujando las desigualdades sociales y abarcando a marginados y excluidos.

La educación no será más un privilegio de élites. La escuela está llamada a ser el eslabón que posibilita semejante cadena de sucesos y a poner a disposición todo su andamiaje de planes, currículos, técnicas evaluativas, herramientas didácticas, prácticas y saberes pedagógicos, para construir a través del discurso formas de subjetividad, agenciadas, entre otras cosas a partir de la producción de un saber/poder sobre los individuos, separado del derecho $y$ de la forma de la ley que se ejerce fuera de ella, a través de uno de sus dispositivos más prestigiosos: la disciplina. Como modalidad discursiva e individualización totalizante prescrita por la racionalidad política de la modernidad, la disciplina "implica una coerción ininterrumpida, constante, que vela sobre los procesos de la actividad más que sobre su resultado y se ejerce según una codificación que retícula con la mayor aproximación el tiempo, el espacio y los movimientos" (Foucault, 2002, p. 124). Sin embargo, también están las disciplinas como saberes propios de la educación escolar que se expresan en "métodos que permiten el control minucioso de las operaciones del cuerpo, que garantizan la sujeción constante de sus fuerzas y les imponen una relación de docilidad-utilidad" (p. 124).

La categoría disciplina incluye y trasciende su compromiso de técnica de adiestramiento de lo físico e incorpora el ámbito del disciplinamiento mental. Además de un cuerpo sujetado somáticamente hay un sujeto colonizado epistémicamente. Se puede hablar de una microfísica/ micropsíquica del poder que se deja ver en asuntos como la utilización exhaustiva del tiempo para medir el progreso de las sociedades y la génesis de los individuos; la articulación cuerpo-objeto/cuerpo-arma/ cuerpo instrumento; el uso de técnicas de imposición de tareas repetitivas, diferentes y graduales de complejidad creciente; la suma de fuerzas elementales para lograr una fuerza productiva y la incursión en prácticas corporales "para depurar y refinar la sensitividad con miras a la liberación individual y a una reformulación de la vida que dé cabida a la expresión, la re acomodación de géneros, la liberación de estereotipos y la espontaneidad" (Pedraza, 1999, p. 76).

Nunca antes la escuela había desplegado estrategias aparentemente tan contradictorias, pero que, por 
su misma ambigüedad, han dado muestras de gran eficiencia al momento de ser requeridas. Esto quiere decir, dispositivos de regulación/regularización y de homologación/singularización de los sujetos, como las pedagogías políticas del cuerpo, referidas particularmente a un saber/poder que se va a materializar en sociedades educativas, normalizadas y formalizadas. Tales dispositivos educativos, en consecuencia, promueven una distribución analítica de sus recursos disciplinarios, a través de regímenes de saber-mediante el poder-que van desde la homologación individual lograda a partir de la administración de una oferta educativa dispuesta según lineamientos curriculares, sugeridos por el Estado pero de asunción obligatoria -más allá de las lógicas de interpretación que se decidan- hasta la instauración de regímenes de poder -mediante el saber- de carácter colectivo que se ocupan de la generalización de pautas de conducta y de la normatización de las desviaciones. Es propio de estas prácticas desencerrar las disciplinas y hacerlas funcionar de manera múltiple y polivalente en el cuerpo, en términos de vigilancia social permanente, exhaustiva y omnipresente, en donde se detenta un sobrepoder ilimitado, que al tiempo que promueve situaciones disímiles y contradictorias (exclusión, ilegalidad, prohibición, consumo, castigo generalizado, restricción, desobediencia, relaciones ambivalentes con el poder, íconos y modelos a seguir), necesita reafirmar sus economías de vigilancia.

Un segundo modo de modernización de la escuela, ha sido enunciado por Martínez Boom (2004), como la escuela competitiva, impulsada por una reconversión educativa que supone "la integración de la educación, la escuela y el maestro a la lógica planteada por la globalización de la sociedad, con lo cual se intenta la refundación de los sistemas educativos" ( $p$. 13). Son rasgos de esta forma de modernización: la modificación de los regímenes de poder/saber pasan de ser movilizados por la demanda para serlos desde la oferta; la planeación de los modos de enseñanza muta en la satisfacción de las necesidades básicas de aprendizaje; el desarrollo ordenado y regulado por las dinámicas disciplinares pasa a entenderse como crecimiento en el ámbito del mercado, regulado ahora, por estándares que evalúan el rendimiento de la institución, los estudiantes y los maestros. El Estado suelta el control, la regulación de la enseñanza y el poder se redistribuyen o, mejor, se localizan en otros agentes que tienen como propósito garantizar la producción de 
sujetos aptos para la competencia, lo que determina la prioridad sobre un aprendizaje socialmente significativo. Soplan vientos de reforma educativa y se promueven discursividades de gestión escolar dramáticamente distintas a las anteriores, con el pretexto de velar por un país capaz de competir en una economía global. El perfeccionamiento de los maestros, la tecnologización del andamiaje institucional, las reformas curriculares y la intervención dentro de las lógicas endógenas de expertos venidos de otras esferas sociales, ponen en juego relaciones de fuerza extrañas a la escuela -de ahí que no sean identificadas ni asimiladas fácilmente- que son condiciones de posibilidad para la nueva escuela en ciernes. "Es a ello a lo que Popkewitz se refiere cuando habla de 'ecología de la reforma' y es allí en donde está la base para la introducción de cambios sustantivos para la escolarización" (Martínez, 1994, p. 286).

Aparecen formas de la individualidad propias del capitalismo flexible, de la sociedad a corto plazo, del rendimiento rápido y del capital impaciente (Sennett, 2000) de las que la escuela tendrá que dar cuenta.

La familia, la escuela, el ejército, la fábrica ya no son medios analógicos distintos que convergen en un mismo propietario, ya sea el Estado o la iniciativa privada, sino que se han convertido en figuras cifradas, deformables y transformables, de una misma empresa que ya solo tiene gestores. [...] Ahora, el instrumento de control social es el marketing, y en él se forma la raza descarada de nuestros dueños. El control se ejerce a corto plazo. [...] Lo importante es que nos hallamos en el inicio de algo [...] en el régimen escolar, las formas de control continuo y la acción de la formación permanente sobre la escuela. La introducción de la empresa en todos los niveles de escolaridad [...] sustituye el cuerpo individual o numérico por una materia "dividual" cifrada que es preciso controlar [...] (Deleuze, 1990, p. 153).

A esto sería pertinente agregar que es preciso des-cifrar.

Expansión y competitividad son discursividades que se constituyen con propósitos y destinos visibles e invisibles, tangibles e intangibles,

[en el contexto de procesos] acumulativos $y$ que se refuerzan mutuamente como la formación de capital y la movilización de recursos; el desarrollo de las fuerzas productivas y el incremento de la productividad del trabajo; la im- 
plantación de poderes políticos centralizados y el desarrollo de identidades nacionales; la difusión de derechos de participación política, de formas de vida urbana y de educación formal, así como la secularización de valores y normas (Habermas, 1989, p. 12).

Todos elementos son propios de la modernidad y escenificados en la escuela como lugar y motivo para la emergencia de dispositivos que van a privilegiar el acontecimiento corporal o a promover su reticulación. A su vez, dichas discursividades son posibles en tanto hay un individuo moderno que, según Pedraza (1999) "cuestiona su historia y piensa, imagina y acomete su propia constitución y transformación y lo hace en buena parte en el cuerpo, con el cuerpo y mediante el cuerpo" (p. 14), a lo que añade: "lo moderno tiene un itinerario y un libreto, por lo que hace el cuerpo" (p. 16). Pensar la tarea pedagógica, desde la perspectiva de los saberes acerca del cuerpo como saberes escolares, es labor ineludible de uno de los artífices de la escuela: el maestro, en cuanto es en su condición de ser corporal que su proyecto vital se realiza. Esta expresión encarnada se hace palpable en su corporalidad y en la corporalidad de sus aprendices, de ahí que su cultura somática ${ }^{4}$ (Pedraza, 1999) vaya a movilizar dispositivos epistémicos como las pedagogías del cuerpo, cuando da cuenta del discurso sobre los propósitos, los hechos y las prácticas que lo educan, cuando las problematiza, las justifica y las sitúa antropológica, política, ética, cultural y socialmente; cuando se pregunta por la naturaleza y la tarea social de los saberes en la escuela, y cuando construye un imaginario de hombre y de desarrollo humano para trazar su prospectiva educativa como sujeto histórico.

El maestro que comprende la complejidad de una cultura de la corporalidad y la multifactorialidad que se juega un proyecto educativo como proyecto de realización de lo humano desde saberes referidos al cuerpo, sabe que está poniendo en sus manos la vida y el futuro de sus estudiantes. En resonancia, debe ser capaz de tomar decisiones para construir entornos de sumisión y obediencia a la normatividad vigente, o bien, oportunidades de resistencia a través de prácticas vinculantes y democráticas que les garanticen a todos aquellos que se educan, la posibilidad

4 Término que refiere a los saberes del cuerpo y sobre el cuerpo de los que disponen las personas y que ponen en escena para habitar socialmente la realidad. 
futura de habitar una corporalidad deseada.

Lidiar con la diversidad inscrita y manifiesta en el cuerpo (estilos cognitivos, dimensión intelectual, representaciones mentales, relación sujeto-objeto-conocimiento, estéticas, moralidad, subjetividad, creencias, deseos, sexualidad, géneros, sumisión, obediencia, resistencia, etc.) y dar la talla en el juego del saber/poder inherente a campos de fuerza y racionalidades promovidas y sujetas a la inter-corporalidad, le permitirá, al maestro, situarse como productor de oportunidades y pretextos de transformación, como gestor o como instrumento de sujeción, y en consonancia elaborarse discursivamente para diseñar ambientes de aprendizaje socialmente significativo o para di-soñar entramados, redes, prospectivas y éticas otras de corporalidades posibles.

La escuela ha sido siempre y es -como se verá más adelante- un reflejo de la sociedad y por ello es sensible a los problemas que en esta se plantean. En la enorme cantidad de críticas y recriminaciones a que la escuela da lugar, hay que ver, como lo hace Snyders (Debesse, 1974, p. 49),

el signo de una sociedad en mutación que no reconoce ya sus valores y su estilo en lo que la escuela propone, y que está en vías de elaboración de un nuevo sistema escolar, a la vez por las obras teóricas y por ensayos efectivos indisolublemente unidos a ellas.

Cuando en una sociedad determinada "persisten aún restos de una educación concebida para un tipo de sociedad diferente, el conflicto es inevitable" (Palacios, 2012, p. 10). Es necesario entonces, situarse en términos de las demandas contemporáneas a la escuela y de la idiosincrasia corporal de sus habitantes, si los sujetos están, como parece, constituidos por saberes acerca de lo corporal.

\section{Racionalidades acerca del cuerpo}

Una racionalidad es, para este propósito, un modo posible en el que se expresa un régimen de saber delimitado históricamente, que deviene discursividad en virtud de formas de enunciación que temporalizan sus objetos discursivos ${ }^{5}$ y gracias a los cuales, dicho saber, a fuerza de ser puesto en juego, termina por naturalizarse ${ }^{6}$. El concepto racionalidad surge en la modernidad, como respuesta a la necesidad

5 La educación como racionalidad moderna refiere sus asuntos a partir de categorías como: desarrollo, crisis, inclusión, globalización, cobertura, capital humano, conceptos que en otros momentos no tendrían el significado que han tenido durante la segunda mitad del siglo $X X$.

6 Cuando se hace referencia a un saber su alcance no se limita solamente a un capital cultural simbólico sino a una serie de prácticas, líneas de acción, decisiones, políticas, estrategias, en fin, a la hechura humana a partir de la cual se crean condiciones de posibilidad (el poder de ser) para su emergencia. 
de configurar el saber dentro de un estatuto de verdad -así se manifiesta el poder- que era adjudicado al discurso, siempre que este fuera una emergencia de la razón. Hoy se puede usar el término racionalidad para referirse a regímenes de verdad [saber/poder], cuya "decibilidad" implícita -modos de enunciación que se justifican, se sustentan a sí mismos y crean su propia posibilidad de ser dichos, ejercen poder- organiza una "repetibilidad" (dispersión, heterogeneidad, regularidad) que naturaliza el objeto discursivo y le otorga su positividad empírica. Vemos pues cómo, el mismo término dejó de ser un concepto privativo de la modernidad aunque su significado original esté justificado por sus lógicas.

Una racionalidad acerca del cuerpo, en una perspectiva ampliada, permitiría presumir que al tiempo que co-existen saberes sobre el cuerpo, diversos y dispersos, hay otros que les pre-existen, ambos, a propósito del cuerpo propio y ajeno y del cuerpo al que se refieren y del que refieren algo. Hasta aquí tenemos alguna aproximación a pensar un saber sobre el cuerpo (científico, ideológico, histórico, cinésico, proxémico, biomecánico, anatómico, antropológico, filosófico, etc.). Pero también se puede pensar un saber del cuerpo: lo que sabemos hacer (hablar, besar, jugar, sumar, acariciar); lo que podemos sentir (amamos, añoramos, reímos y lloramos, presentimos un antiguo amor a la distancia); lo que decimos como cuerpo o con el cuerpo (danzamos, señalamos, gesticulamos, volteamos a mirar cuando nos llaman, movemos los brazos y las piernas cuando estamos en el agua, soñamos cuando existimos para un ser amado) etc.; que ha sido enunciado tradicionalmente como lenguaje corporal o lenguaje no verbal, etc.

Surge, entonces, el asunto más relevante al momento de situar estos saberes, y aun más, estas racionalidades en el ámbito de la escuela. Ya se ha visto que es territorio propicio para configurar, adoptar o rechazar dispositivos, en cuanto produce y es producto de regímenes de saber/poder, que se van a expresar a través de cuerpos y en tanto cuerpos. Una racionalidad ampliada de cuerpo consideraría saberes encarnados en el cuerpo, valga la redundancia y saberes sobre el cuerpo propio y de otros cuerpos anteriores a este, contemporáneos y futuros. La cuestión consiste en entender las relaciones y las implicaciones de estos dos modos de saber del cuerpo en el momento de hablar por ejemplo, de formar, capacitar, instruir, estandarizar, dictar, cooperar 
y demás situaciones que los ponen en tensión. Esto es fundamental si se piensa en los efectos de estar sujeto a una racionalidad particular y desconocer a qué dispositivos obedece. A continuación se nombran algunas racionalidades herederas de dispositivos de la modernidad.

En El tocar, Jean-Luc Nancy, Derrida (2000) dice:

Al parecer no se puede tocar más que un cuerpo extenso, pero no toda extensión es necesariamente tocable, hay una extensión inteligible o sensible pura, una extensión no empírica [...] la boca lugar único [...] sería el lugar común de los inconmensurables en cuestión: el cuerpo y el alma -la mente o el pensamiento- (p. 161).

Con este argumento, Derrida se refiere a la inconmensurabilidad entre dos maneras de ser extenso, en tanto extensión del cuerpo y extensión de la psique (recordando a Descartes), y termina citando al propio Nancy: "La extensión inconmensurable del pensamiento es la abertura de la boca" (Nancy, 1992; citado por Derrida, 2000, p. 161). La encarnación del pensamiento, desde la mirada de Deleuze y Nancy, se realiza en el contacto de la palabra con la piel de la boca. El verbo se hace carne porque la palabra entra en contacto con la oque- dad de la boca, se aloja allí, en la embocadura, en el espacio entre los labios. Así, la boca que se abre es la que "da a luz a ego", según Nancy, y evoca poéticamente a esos otros labios que se abrieron otrora para traer al mundo a ese yo.

No toda extensión es necesariamente tocable, pero aquella que no se puede tocar se puede inteligir, por tanto, nada se sustrae a la posibilidad de ser cuerpo, lo cierto es que aún lo solamente inteligible también pasa por la encarnación. Sobre la unión del alma y el cuerpo, y a propósito de Descartes ${ }^{7}$, quien en su concepto no tiene nada que decir de esto, puesto que solo ha referido la posibilidad de esta unión a través de nociones míticas en el sentido platónico de la palabra, Merleau-Ponty (2006) cita el siguiente fragmento de una carta de Descartes a Elisabeth el 28 de junio de 1643: "sólo sirviéndose de la vida y de las conversaciones, y absteniéndose de meditar y de profundizar en las cosas que ejercitan la imaginación, se aprende a concebir la unión del alma y el cuerpo". Junto con esta ironía, cierra el desencuentro diciendo: "la unión solo puede ser conocida por la unión", planteando al respecto de la carta, no ya la conciliación de la unión de hecho y la distinción de esencia sino el interrogante frente a

\footnotetext{
Este texto de Derrida dedica el capítulo III, "Esto es mi cuerpo", a argumentar la imposibilidad de concebir el cuerpo en una racionalidad cartesiana: disyunción en cuerpo-mente e invita a varios autores a él.
} 
"cómo puede ser que haya un sector que uno no pueda pensar" (Merleau-Ponty, 1945, p. 15).

En el tao de la física, Fritjof Capra (1975) dice:

La teoría de Santiago ${ }^{8}$ nos da, a mi manera de ver, el primer marco científico coherente que soluciona el divorcio entre mente y materia. Mente y materia ya no son conceptos pertenecientes a categorías distintas, sino que representan dos aspectos complementarios del fenómeno de la vida: el aspecto proceso y el aspecto estructura. La mente es el proceso de la vida, el proceso de la cognición. El cerebro (y por supuesto la totalidad del cuerpo) es la estructura a través de la cual este proceso se manifiesta (p. 15).

"La carne no es otra forma de llamar al cuerpo, es más bien (...) otro modo de decir que el cuerpo es más que cuerpo, es carne, masa interiormente trabajada, a la vez sensible y sentida" (Larios, 2005, p. 1). "La mente es el cuerpo que se experimenta a sí mismo", dice Carlos Muñoz Gutiérrez (2009, p. 1).

[...] uno de los más importantes avances en la ciencia en los últimos años es la convicción de que no podemos tener nada que se asemeje a una mente $o$ a una capacidad mental sin que esté totalmente encarnada o inscrita corporalmente, envuelta en el mundo. Surge como una evidencia inmediata, inextricablemente ligada a un cuerpo que es activo, que se mueve y que interactúa con el mundo. (Varela, 2009, p. 1).

Todas estas miradas han formado parte de las discursividades de la modernidad. Indudablemente la fragmentación mentecuerpo parece superada. ¿Podríamos asumir en consecuencia, que los regímenes de saber/poder que gobiernan los dispositivos escolares están enterados de esta verdad?, y por tanto, ¿han de haber creado condiciones de posibilidades para la configuración de racionalidades corporales de la completud? Así mismo, estas racionalidades habrían de haber alimentado dichos dispositivos de tal manera, que se puede esperar que tanto dentro de la escuela como fuera, en lo que respecta a ella, esto sea, como se dice: una verdad de Perogrullo.

8 Capra se refiere a una teoría desarrollada por Humberto Maturana y Francisco Varela en el libro El árbol del conocimiento, situada en la perspectiva biológica del conocimiento, y que después Varela elabora como "cognición enactiva", en su libro Conocer. 
Los dispositivos y las racionalidades en su calidad de regímenes de saber/poder, decíamos, se comportan según las instancias que los delimitan, así, el poder se puede ejercer vía el saber, cuando sus instancias de delimitación son connaturales al saber, como la escuela. El saber, así mismo, se puede ejercer vía el poder cuando las instancias que lo delimitan son connaturales al poder, como la dominación. ¿Cuál es la relación entre esto y los saberes acerca del cuerpo? ¿Qué instancias de delimitación se ponen en escena en el marco de qué dispositivos y de qué racionalidades en la escuela? Considérense dos estrategias en las que se han apoyado los regímenes de saber/poder escolares para configurar dispositivos y racionalidades acerca del cuerpo: el miedo y la ignorancia.

¿Por qué la disciplina como dispositivo de poder que actúa vía el saber es tan eficiente generalmente? Los cuerpos en las disciplinas de adiestramiento corporal, como ya se mencionó, además de estar sujetados orgánicamente, están colonizados epistémicamente, en el sentido de que se les convoca a memorizar y a mecanizar un amplio repertorio de prescripciones (saberes del cuerpo) desde la ceguera total de las maneras en que ellas, como notas musicales, se van registrando en cada fibra y van dejando impresa, en el pentagrama somático, la melodía que debe ser reproducida. El asunto es que esa melodía no solo es des- conocida por el ejecutante, sino que las razones para componerla (saberes sobre el cuerpo), tampoco están a su alcance.

El cuerpo así, merced a su ignorancia, es instrumento del poder, y el aprendizaje socialmente significativo del que hablaba Martínez Boom (2004), es la racionalidad que lo moviliza.

Muchos son los dispositivos escolares que se mueven en estas lógicas. La evaluación en la escuela, como dispositivo de saber, que actúa vía el poder, es igualmente efectiva. La racionalidad que la moviliza, es la responsabilidad que se le atribuye de entregarle a la sociedad cuerpos competitivos que respondan a las necesidades del mercado. Los estándares de rendimiento, para los cuales actúa, se juegan en las arenas del capitalismo globalizado, enmudeciendo e invisibilizando cualquier singularidad extraviada que se atreva a contradecir sus lógicas. La escuela también tiene sus prisiones y es reconocida por agenciar este género de saber/poder que se materializa al "conducir conductas y disponer de su probabilidad induciéndolas, apartándolas, facilitándolas, dificultándolas, limitándolas, impidiéndolas" (Castro, 2004, p. 380).

La película india de Taare Zameen Par, Every child is special, está basada en la vida de Ishaan Awasthi, un niño con dislexia. Nikumbh, su maestro de arte, entiende que el niño está atrapado en su cuerpo, en la velocidad con que le pasa la vida 
y que él no puede asimilar, su cadencia tiene otra longitud de onda, no alcanza a leer el mundo desde los textos que le impone la sociedad. ¿Qué es lo que alerta al maestro y lo deja paralizado acerca del niño? En su primer día de clases -hay que decir que también trabaja en una institución para niños con debilidad mental- entra al aula vestido de payaso, pero antes se ha escondido y toca la flauta sin que los niños sepan de dónde proviene la melodía. Cuando ingresa al salón de clase en medio de la sorpresa y la emoción que despierta, todos los niños gritan, brincan, lo siguen por el espacio encaramándose a los pupitres, asomándose por las ventanas, desordenándolo todo, como si hubieran entrado en la magia de la vida, tan ausente a veces en nuestras escuelas. Hay un niño que no reacciona, sigue literalmente petrificado mirando al vacío, un vacío que se siente muy interior cuando se mira a través de sus ojos. Esto deja fuera de lugar a su maestro, él que ha probado ser motor y aliento de otros niños menos dotados. ¿Cómo es que no puede conmover a este? El sentimiento de desolación que le produce el comportamiento de Ishaan, queda registrado en su carne tan profundamente, que él mismo va tornándose inmóvil, su cuerpo es presa de la impotencia que produce la ignorancia y el miedo. Sin embargo se resiste a quedar sujeto y toma la decisión no solo de averiguar qué pasa (saber sobre el cuerpo) sino de actuar para resolverlo (saber del cuerpo), lo cierto es que, cuando lo logra, uno ve la plenitud encarnada en el poder de saber.

¿Cómo hace Nikumbh para devolverle la esperanza a Ishaan? Lleva a los niños fuera del aula, a un lugar en donde hay un lago grande rodeado por montañas para que cada uno invente algo utilizando los materiales que escoja. Ishaan construye un barco-avión con palos y hojas y le inventa una hélice que también funciona como alas; de pronto, lo pone en el agua y el aparato empieza a moverse ante los ojos atónitos de sus compañeros y de su maestro, que después de un momento descubre que también puede volar. La mente de Ishaam no tiene fronteras, es inconmensurable, solo necesita que la dejen encarnarse en sus manos para que aparezca ese yo recóndito que tal vez no ha encontrado razones para dejarse ver. ¿Cuántos niños de estos tenemos escolarizados?

El dispositivo de sexualidad que ha descrito Foucault, atraviesa medularmente a la escuela, pero, ¿qué es lo que le confiere tal poder? Este dispositivo en la escuela funge también como 
racionalidad que se sirve de otros dispositivos: la discriminación y la exclusión. Esta racionalidad dispone estrategias que reticulan y fragmentan la vida escolar en un campo de fuerzas cuyas coordenadas se pueden rastrear, entre otras cosas, en la categorización dicotómica de los cuerpos como masculinos y femeninos y desde ahí, la determinación de regulaciones que promueven prácticas de desigualdad según la delimitación de diferencias de género y edad (situación que evita contactos innecesarios que podrían distraer de asuntos más urgentes: las obligaciones escolares). Algunas pistas para explicar el efecto del dispositivo de sexualidad, que entre otras cosas me ha permitido darle sentido a la naturaleza distante del poder/saber, me las ha ido dando, en el gimnasio en donde entreno, un evento que presencio diariamente -iba a decir "cuando interactúo", pero eso es precisamente lo que no logro hacer-. Estoy ahí como un alguien desintegrado del contexto, observando a todos estos jóvenes entre teléfonos celulares, que usan para llamarse de una máquina a otra, a menos de un metro de distancia, y que se vigilan de soslayo, controlando en el otro el más mínimo movimiento, sin poder acceder a sus lógicas, pues no soy admitida por ellos, ni siquiera sé si se dan cuenta que estoy ahí.

La seducción que como ritual del cuerpo, había sido relegada en la cultura occidental al dominio de lo femenino, parece constituir hoy una forma irónica y alternativa que rompe la referencia del sexo como espacio de deseo y lo convierte en campo de juego y de desafío. Me veo seducida a mi vez porque esto me impele a entrar en un juego movedizo de suposiciones que me apartan de una sola verdad constitutiva del sexo. Refiriéndose a Narciso que se mira en el agua no ya para admirarse sino para reencontrar-se con su hermana gemela desaparecida, Baudrillard (2008) dice: "El espejo del agua no es ya una superficie de reflexión, sino una superficie de absorción, [...] la seducción se funda en la atracción de lo mismo, en una exaltación mimética de su propia imagen, o en el espejismo ideal del parecido" (pp. 67 y 68). Baudrillard está construyendo una argumentación alrededor del seductor y del seducido, y del hecho de que la persona seducida encuentra en la otra lo que la seduce, el objeto de su fascinación lo constituye su propio ser lleno de encanto y de seducción, la imagen amable de si mismo. "I'll be your Mirror'; 'Yo seré tu espejo' no significa 'Yo seré tu reflejo', sino 'Yo seré tu ilusión'. Seducir es morir como realidad y producirse como ilusión" (Jeudy, citado por Baudrillard, 2008).

Inmediatamente me viene a la mente el concepto de dividualidad de Deleuze, de esta homogeneidad construida desde afuera, sobre el cuerpo de los jóvenes como potentes consumidores y de hecho como grandes consumidores de cultura 
somática (Pedraza, 1999). ¿Asistimos a nuevos modos de subjetividad en donde la diferencia está precisamente en garantizar la semejanza? ¿Se está dando un narcisismo emergente que consiste en hacer a los otros a imagen y semejanza, desde el acto de mirarlos y a la vez, reflejarse en ellos, para rescatar la ilusión de ser ese yo personalizado, en un ritual ficticio de singularización que deviene mímesis y homologación? José María Blasco (1992), en el texto El estadio del espejo: introducción a la teoría del yo en Lacan, dice:

cualquier otro a quien yo ame en algo, aquel a quien vea con buenos ojos, narcisismo ya desde Freud, estará para mí en el lugar de esa imagen alienante en la que confluyen mi ideal del yo y mi cuerpo sin fragmentar. Es por eso que Lacan puede decir en La agresividad en Psicoanálisis ${ }^{9}$ que en el momento en que al otro ya no lo amo sino que deseo agredirlo, lo que está en la base de mi agresión es el retorno a mi cuerpo fragmentado: en el momento en que ya no se sostiene la identificación con el otro, la imagen falla. [...] Y de ahí me vendrá, de lo que el otro es, sabe y dice, pero yo desconozco, lo que yo creeré ser, querré saber, y pensaré pensar, pensando pero sin ser, o siéndolo sin pensar (pp. 8-9).

La dividualidad, en tanto racionalidad heteroestructurante del cuerpo, estaría siendo hechura de dispositivos psico/biopolíticos centrados

[en el] cuerpo transido por la mecánica de lo viviente [...] el hombre occidental aprende poco a poco en qué consiste ser una especie viviente en un mundo viviente, tener un cuerpo, condiciones de existencia, probabilidades de vida, salud individual o colectiva, fuerzas que es posible modificar y un espacio donde repartirlas de manera óptima. (Zamorano, 2011, p. 1).

Disciplinas del cuerpo consciente y regulación de las mentes en el terreno de lo inconsciente, son de esta manera instancias de delimitación de racionalidades que acceden a territorios corporales acéfalos. Es inminente dilucidar los juegos estratégicos 
en los que se juegan los jóvenes con estas prácticas o las prácticas en las que el mercado los ha puesto deliberadamente en términos de funciones, productos y comercio del cuerpo, al punto de pensar ellos mismos que obedecen a sus propias ilusiones, cuando en realidad son sujetos, o mejor objetos, de estrategias descaradas de seducción. El consumo de actividades corporales tras la belleza, la división geográfica y sexual del trabajo muscular; el consumo de los cuerpos que se agotan en el mirar y querer emular; el dolor, las privaciones y el sufrimiento de quienes invierten en el cuerpo y la legitimación de la violencia, conciernen a las maneras de ver el cuerpo humano y a las formas de definir sus zonas de sombra, "que no cesan de variar a lo largo de la historia y de acuerdo con los presupuestos de la cultura" (Branco, 2007, p. 340).

Esos presupuestos son precisamente la razón de ser de la escuela. Estamos asistiendo en las últimas cinco décadas, a un vértigo de mutaciones que la raza humana no había experimentado en toda la historia de la civilización. En los últimos sesenta años se han transformado nuestras realidades de manera tan dramática, que han generando nuevas formas de corporalidad en niños, jóvenes y adultos (Mejía, 2010, pp. 56-58). Estos cambios están representados en fenómenos que se dieron a nivel de las poblaciones y no ya de los individuos, de ahí su impacto: la transistorización o el desarrollo del radio en la década de 1940 -primera globalización cultural-; la imagen o el desarrollo de la televisión en la década de 1960, umbral de separación entre lo real y lo virtual, dando paso a la ambigüedad; la informática o el desarrollo de la versión PC de los computadores en los años 1980, en donde la memoria deja de ser una función particularmente humana y es sacada del cuerpo; la telemática, o unión de lo escrito, lo oral y lo digital, visibilizada en la internet, que da lugar a conceptos como glocalidad, industria cultural de masas e hibridación; y la biotecnología o el desarrollo de las clonaciones y la investigación sobre genoma humano, en la segunda parte de los años 1990 y el inicio del nuevo milenio, época caracterizada por lo que llaman algunos autores como de vacío y de pluralización ética. La cara del mundo modificó su fisonomía en un periodo tan insignificante, si se piensa en lo que ha sido la evolución de la especie humana, que produce escalofrío imaginar lo que está por venir.

\section{Campos de fuerza: prácticas de sujeción y de resistencia}

Los gestos, los estereotipos, los cánones estéticos, los emblemas, las cartografías cinésicas que codifican las formas de los dedos, del rostro y el tipo de arrugas; la proxemia que codifica el espacio en términos de distancias y ángulos de acercamiento al otro para inferir topografías de 
la conciencia o de las intenciones; las prácticas de autocontrol y estandarización anatómica; en fin, son somatotipos estratégicos que funcionan hoy como racionalidades al servicio de dispositivos analíticos de la corporalidad. "Existe la sonrisa desincronizada del delirante, la mirada huidiza del autista, o la mirada perdida del estupor. El cuerpo no puede ser una página en blanco, un pretexto" (Descamps, 1992, p.10). La economía capitalista es responsable de una amplia variedad de dispositivos para modelar cuerpos y subjetividades.

La alianza estratégica de la ciencia y el mercado es actualmente, artífice de la fusión hombre/tecnología que Paula Sibilia (2010) ha denominado la hibridación orgánico-tecnológica, como propuesta de planificación de la especie humana en el contexto de racionalidades como la posnaturaleza de los organismos genéticamente modificados. Se acude a una nueva narrativa cosmológica:

Sin duda, lo que entendemos por naturaleza no es algo fijo o inmutable. Se trata también de un concepto que no deja de ser una invención de la humanidad, una idea que varía en las diversas sociedades según los tipos de saberes generados por cada época. (Sibilia, 2010, p. 105).

Resultado de esta fusión son también saberes del cuerpo que se encarnan en mentes de orden superior. Una mente así,

superpenetrante, capaz de percibir rápidamente cualquier relación causal, podría indicarnos, a partir de la estructura de bandas de cromosomas, si un huevo se tornaría bajo condiciones adecuadas, en un gallo negro o una gallina pintada, una mosca o una planta de maíz, un rododendro, un escarabajo, un ratón o una mujer. (Schrodinger, 1985, p. 68).

¿Se estará dando, en un futuro no ya muy lejano, el alumbramiento de prácticas de resistencia a la intrincada red de controles, que instauraron las biopolíticas para multiplicar el rendimiento humano y llevar el cuerpo a sus bordes? O, por el contrario, estamos asistiendo a la refundación de dispositivos de encerramiento bioinformático, en donde el cuerpo llegado el momento en que su voluntad dependa de programas de silicona y no de la posibilidad encarnada de la ilusión y el deseo, le ¿habrá vendido su alma al diablo? La residencia de lo 
humano podría estar localizada en estas racionalidades de lo transhumano y en el engranaje de técnicas de intervención del cuerpo; aunque sabemos que, en el terreno de las emociones, pasiones, sentimientos y sensaciones, la tecnociencia solo ha tenido fracasos.

Hay otras discursividades corporales que han existido siempre, y que gracias a haberse dado en otras épocas, en el contexto de racionalidades que no las satanizaban, fueron respetadas, pues obedecían a dispositivos de la normalidad: las cosas eran así, o se había determinado que así fueran. Estas son las prácticas que se han estado discutiendo y difundiendo en el Ciclo Rosa, un dispositivo de confluencia de academia, arte y activismo fundado en 2001 por la Pontificia Universidad Javeriana, para "promover el reconocimiento de derechos de sectores sociales que han sido marginados o excluidos de la condición de ciudadanía plena" (Serrano, 2006, p. 10), y al que asisten jóvenes en edad escolar. Uno de sus propósitos es develar y comprender prácticas de la transexualidad, la homosexualidad $y$ el transgenerismo.

La dimensión de género y sexualidad de la violencia atraviesa hechos tan contundentes como el que los cuerpos de hombres jóvenes sean la carne de cañón de las guerras y de los efectos de formas de masculini- dad hegemónica que privilegian el riesgo sobre el propio bienestar, así como el que los cuerpos de las mujeres sean tanto campos de batalla de las relaciones de género como el botín que se reparten los actores de los conflictos armados, pero no solo hay diferencias entre la violencia que afecta a hombres y mujeres: también existe la que afecta a unas mujeres y no a otras, a unos hombres y no a otros. Así sucede con las discriminaciones, exclusiones $y$ negaciones con que se enfrentan a diario y a lo largo de su vida, muchas personas que viven otras sexualidades y otros géneros. (Serrano, 2006, p. 11).

Estos saberes emergen en el cuerpo normalmente a temprana edad y se convierten en la mayoría de los casos, en lastres que ponen de presente la intolerancia y el poder para silenciar saberes válidos, desplegados por diferentes colectivos humanos como la escuela, la familia, y la sociedad, en virtud de su ignorancia y de su miedo. Cuerpos encerrados, atrapados en su propia naturaleza, sometidos y empujados a prácticas de resistencia azarosas, oscuras, escondidas en el confinamiento de la sujeción, a manos de una sociedad 
que no hace nada más allá de invisibilizar, porque no sabe o no quiere saber sobre esto. Lo dramático es que sí sabemos que hay un cuerpo que encarna "un fuerte anhelo de transformación de sus genitales mediante una cirugía llamada: reasignación sexual [...] o que sienten un deseo profundo de ser mujer" (Talero, 2006, p. 42) o, que simplemente encuentra en un cuerpo de su mismo género el objeto de su erotismo y no puede albergar casi ninguna esperanza, de ser corporalmente genuino. "Yo no me sentía marica, esto que me invadía era distinto [...] no se trataba de mi orientación sexual, esto que sentía, tenía sus raíces en mi esencia" (Talero, 2006, p. 37). Así se expresa un joven adolescente que dice haber empezado a vestirse con las ropas de su hermana cuando apenas contaba con 7 años. Estamos hablando de un niño de quinto de primaria que empieza a saber de su cuerpo en un entorno en donde ese saber no es admitido, y en donde las discursividades a las que tiene acceso no le dan información sobre lo que siente. Un niño a quien el régimen de verdad sobre su cuerpo lo tilda de degenerado.

El mundo es un laberinto de contingencias corporales. Los dispositivos y las racionalidades de la modernidad han determinado sus perfiles. La razón, la voluntad de saber, la verdad, el mercado, el lucro, la estética, el tener, han sido racionalidades que en ocasiones, parecen habernos desviado de la intención de querer hacernos cada vez más humanos. ¿En qué consiste estar sujeto o resistirse, cuando la condición propia de lo humano es estar en relación con otros, con algo y con alguien y en algún lugar, estar sujeto a un nombre, a los ciclos vitales, a la sensación de hambre, a mirar, a oler, a oír, a habitarse?

Estar sujeto es conestar, adherir, actuar; en consecuencia, elegir, optar. Percibir es un imperativo de la condición corporal, basta con estar vivos para ser en razón de algo. Ocupamos un espacio, somos sentidos por otros, nuestra condición pertenece a las carnalidades plurales. No se puede ser rueda suelta ni siquiera aislándose, soltándose del eslabón, estando completamente solos o para nadie. A pesar de todo siempre vamos a estar ahí, en últimas, para nosotros mismos. A pesar de las matrix ${ }^{10}$ y las cavernas $^{11} \mathrm{o}$ tal vez porque existen, hay posibilidades de resistencia. Esta última es una condición de la sujeción, y si no,

10 La referencia se hace a la película Matrix en donde, como sabemos, los humanos están sujetos a una matriz lógica que los determina.

11 Se refiere a la novela de José Saramago, La Caverna. 
¿a qué se resiste? La sujeción es una condición de la resistencia, y si no, ¿a qué se resiste? Se está sujeto al miedo y a la ignorancia y por eso mismo se tiene la potencia de resistirse a ellos. La posibilidad de estar en un lado o en el otro, de hecho la realidad es que estamos en ambos lados -el asunto es saberlo-, la otorga el poder de saber. El saber empodera y la ignorancia y el miedo someten. Tanto poder saber como ignorar se hacen en el cuerpo, con el cuerpo y mediante el cuerpo. Si la razón ha sido como sabemos hechura de la lógica, ¿qué pasa si nos atrevemos a proponer algo así como dispositivos analógicos ${ }^{12}$ al mando de racionalidades que se mueven en ámbitos de la razón no convencional y al margen de lo previsto?

En la vía de Merleau-Ponty, Jean François Lyotard, siguiendo la tradición fenomenológica, rompe con el carácter representativo de la pintura y aborda el cuerpo desde el ámbito del deseo -en una perspectiva claramente freudiana- acuñando una categoría de la que más tarde se va a servir Deleuze, para elaborar su propuesta del cuerpo sin órganos: lo figural. Lo figural en tensión con lo figurativo, es la expresión "de fuerzas en conflicto que operan sobre el cuerpo" (Brigante, 2005, p. 79). La síntesis fenomenológica de Lyotard

12 Analógicos no se refiere por supuesto a alógicos -sin lógica- sino a lógicas propias de racionalidades paralelas como la metáfora o la analogía, y a otras que normalmente han sido habituales de ámbitos como las artes, pero de ninguna manera privativas de estos. es superada por Deleuze, cuando, a la luz de la pintura de Bacon, se da cuenta de que lo que se sugiere es más bien una única sensación que atraviesa al cuerpo y lo transforma en un cuerpo intensivo múltiple, en donde se verifica una explosión del sentir que se expresa en diferentes niveles, una encarnación irradiada sin un centro definido. Las fuerzas del color, de la textura, de las sombras y las claridades van configurando un lienzo que no traduce ya la figura, sino un campo de tensión sensorial que gravita de manera desorgánica, en el sentido de la no confluencia en el orden y más bien de la exacerbación de la carne que es puro movimiento. "No hay solamente un cuerpo representado sino la posibilidad de ver a través del color, las fuerzas que lo permean" (Brigante, 2005, p. 180).

El cuerpo sin órganos $(\mathrm{CsO})$ atribuido a Gilles Deleuze ${ }^{13}$ deviene paisaje-cuerpo. Este milagro es posible gracias al color y no al trazo, no estamos al acecho de la forma sino de la sensación, no se pretende la unidad corporal y la tranquilidad de lo estable, la pretensión está situada más bien en el dislocamiento de lo convencional, las seguridades que provienen de los cuerpos dóciles y prefigurados se revientan, desbordan los marcos de lo prescriptivo y de lo descriptivo, y la fijación de

13 Esta referencia la hace José Luis Pardo en: Curso de verano PEI Obert, Julio de 2010, organizado por el Museo de Arte Contemporáneo de Barcelona. http://www.filosofia.net/materiales/ cogitos/cez7.html 
la figura entra en el decurso de lo des-figurado. El color deviene racionalidad para el dispositivo analógico de lo figural. Esta imagen puede llegar a ser aterradora o inspiradora de nuevas racionalidades, para los regímenes de saber que tienen el poder de propiciar en niños y adolescentes -aquellos que adolecen, que van camino de poseer-, la apertura del acontecimiento y la posibilidad de experimentar-se cuerpo completo. Ese concepto de lo figural deriva en un procedimiento que Deleuze ha descrito como el diagrama (Sánchez 2005, p.233). Este es un proceso pictórico que debe sustraerse de los clichés que existen en la manera misma como el artista asume el lienzo.

El trabajo del pintor no empieza con el lienzo vacío sino que está antecedido por el esfuerzo para distanciarse con respecto a la docilización que hacen de las figuras y de la percepción las prácticas hegemónicas. [...] el diagrama, en consecuencia, es la expresión de la ruptura que hace el pintor, gracias a trazos significantes, con las figuras y percepciones a las que estamos familiarizados para introducir un mundo nuevo que posibilita la aparición de lo figural. (Sánchez, 2005, p. 233).

Los dispositivos analógicos que se han descrito están constituidos y son posibles gracias a racionalidades paralelas, en donde los regímenes de poder están delimitados desde instancias que ya no se expresan solamente como saberes del cuerpo o saberes sobre el cuerpo, sino como: saberes del cuerpo sobre el cuerpo. Cuerpos que dibujan cuerpos. A propósito, el siguiente comentario del pintor Luis Caballero:

Dibujar es analizar. Es escoger [...] para recrear la emoción que se siente [...] no es reproducir la realidad sino tratar de apropiarnos la emoción fugaz y siempre distinta que produce en nosotros esa realidad. Degas lo sabía muy bien cuando decía que el dibujo no es la forma sino la manera de ver la forma. (Sánchez, 2005, p. 218).

"Hay pintores que pintan su vida en los cuadros y otros que pintan manzanas, por ejemplo, y no están poniendo nada de su vida en las manzanas. El tema es lo de menos, lo importante es crear tensión" (Sánchez, 2005, p. 231). 
Esa tensión está a la mano cuando se permite la emergencia de otras racionalidades, de otros lenguajes expresivos, de la palabra que no solo pasa por la oquedad de los labios sino por el vértigo de la velocidad y de la pirueta, de la polifonía, del intérprete de otras corporalidades, rasgos propios de saberes como los del arte. ¿Es la escuela un lugar y un motivo para la realización de la vida? ¿Cuáles son los saberes que le dan vida al cuerpo y cómo se juega el poder de saber que los hace posibles?

Saber es rasgo de humanidad en escenarios distantes de aquellos en donde la predeterminación de pautas formatea y deforma, dejando de lado la voluntad y la ilusión que se diluyen con el cuerpo.

La guerra se presenta como la experiencia pura del ser puro, en el momento mismo de su fulgor en el que se queman los decorados de la ilusión. [...] La prueba de fuerza es la prueba de lo real. Sin embargo, la violencia no consiste tanto en herir y aniquilar como en interrumpir la continuidad de las personas, en hacerlas desempeñar papeles en los que ya no se encuentran, en hacerles traicionar, no solo compromisos, sino su propia sustancia. (Levinas, 1997, pp. 48 y 49).

\section{Postscriptum}

Desde que tengo memoria estoy en la escuela. Cuando era muy niña acompañaba a mis tías que eran maestras, y jugaba a la escuela en el garaje de mi casa; mi madre me lo permitía. Luego fui a la escuela como todos los niños hasta que me gradué de bachiller. Más tarde fui maestra de escuela yo misma durante más de veinte años y ahora soy asesora en procesos de acreditación y de renovación curricular. La escuela siempre ha sido un lugar que me sitúa en mis bordes. La educación es una de mis razones vitales, y es tan enigmática que logra mantener mi interés por descifrarla, pero la escuela de hoy, desborda cualquier expectativa. El reto de hacer de la escuela un motivo para sentirse vivos, en donde haya cabida para dispositivos analógicos y racionalidades paralelas, está entre otras cosas, en hacer de ella, el lugar para una corporalidad completa. Para que esto suceda, hay que darle la palabra al cuerpo y hay que darle cuerpo a la palabra. 


\section{Referencias}

Aisenson, A. (1981). Cuerpo y persona. México: Fondo de Cultura Económica.

Aldana, E. y Caballero, P. (1997). La reforma educativa en Colombia: desafíos y perspectivas. Bogotá: Instituto ser - Preal.

Baudrillard, J. (2008). De la seducción. 12ª ed. Madrid: Editorial Cátedra.

Blasco, J.M. (1992). El estadio del espejo: introducción a la teoría del yo en Lacan. Ponencia en el ciclo de conferencias Psicoanálisis a la vista. Ibiza. Recuperado de: http://www.epbcn.com/personas/jmblasco/publicaciones/19921022.pdf.

Branco F., A. (2007). Cuerpos saludables a la sombra del riesgo. Escuelas, vida activa y biopolítica informacional. En: Z. Pedraza (comp.). Políticas y estéticas del cuerpo en América Latina. Bogotá: Universidad de los Andes. Pp. 331-356.

Brigante, A. (2005). La relación del cuerpo con el arte: del cuerpo mecánico al cuerpo sin órganos. En: A.M. Brigante et al. El cuerpo, fábrica del yo: producción de subjetividad en el arte de Luis Caballero y Lorenzo Jaramillo. Bogotá: Editorial Pontificia Universidad Javeriana. Pp. 65-84

Butler, J. (2002). Cuerpos que importan, sobre los límites materiales y discursivos del sexo. Buenos Aires: Editorial Paidós.

Capra, F. (1983). El tao de la física. Málaga: Editorial Sirio.

Capra, F. (1996). La trama de la vida: una nueva perspectiva de los sistemas vivos. Barcelona: Editorial Anagrama.

Castro, E. (2004). El vocabulario de Michel Foucault. Un recorrido alfabético por sus temas, conceptos y autores. Universidad Nacional de Quilmes. Recuperado de: http://es.scribd.com/ doc/11414155/castro-edgardo-el-vocabulario-de-mfoucault

Debesse, M. y Mialaret, G (dir), (1974). Historia de la Pedagogía, Oikos-Tau, Barcelona.

Deleuze, Gilles. (1990). Conversaciones 1972-1990. Traducción de José Luis Pardo.

Edición electrónica de www.philosophia.cl / Escuela de Filosofía Universidad ARCIS.

Derrida, J. (2000). El tocar, Jean-Luc Nancy. Buenos Aires: Amorrortu Editores.

Descamps, M. (1992). El lenguaje del cuerpo y la comunicación corporal. Barcelona: Ediciones Deusto.

Foucault, M. (1970). La arqueología del saber. Buenos Aires: Siglo Veintiuno Editores. 
Foucault, M. (1977). Historia de la sexualidad I. La voluntad de saber. Madrid: Siglo XXI Editores.

Foucault, M. (2002). Vigilar y castigar. Nacimiento de la prisión. Buenos Aires: Siglo XXI Editores.

Habermas, J. (1989). El discurso filosófico de la modernidad. Buenos Aires: Taurus.

Larios, V. (2005). Quiasmo cuerpocarne. Revista A Parte Rei. 42. Noviembre 2005. http://serbal. pntic.mec.es/ cmunoz11/larios42.pdf

Levinas. Emmanuel. Totalidad e infinito. Ensayo sobre la exterioridad. Salamanca 1997. http:// espacethique.free.fr/articles. php?lng=fr\&pg=178

Martínez, B., A. (2004). De la escuela expansiva a la escuela competitiva: dos modos de modernización en América Latina. Barcelona: Anthropos Editorial.

Martínez, A. y Álvarez, A. (comp.) (2010). Figuras contemporáneas del maestro en América Latina. Bogotá: Magisterio y GHPP.

Mejía, M.R. (2010). Las culturas juveniles: una forma de la cultura de la época. Educación y ciudad, No 18, 49-75.

Merleau-Ponty, M. (1945). Phenomenology of perception. Nueva York: Routledge.

Merleau-Ponty, M. (2006). La unión del alma y el cuerpo en Malebranche, Biran y Bergson. Ediciones Encuentro S. A.

Muñoz G., C. (2009). La disolución del problema mente-cuerpo. $R e$ - vista A Parte Rei, 31. http://serbal.pntic.mec.es/ cmunoz11/ carlos31.pdf

Narodowski, M. (1999). Infancia y poder. La conformación de la pedagogía modera. Buenos Aires: Aique.

Ortega y Gasset, J. (1983). Ensimismamiento y alteración, en: Obras completas. Revista de Occidente, Madrid, vol. V.

http://montsepedroche.files.wordpress.com/2010/01/textos_ortega.pdf

Palacios. Jesús. (2012). La cuestión escolar. Cátedra Pedagogía 1. Problemática Social y Pedagógica. Texto 7. Módulo 7.

Pedraza, Z. (1999). En cuerpo y alma. Visiones del progreso y la felicidad. Bogotá: Universidad de los Andes.

Rodríguez J., A. (2000). El poder una circunstancia en el pensamiento de Foucault. Revista Ciencias Humanas, 24. Recuperado en diciembre de 2000 de: http:// www.utp.edu.co/ chumanas/ revistas/revistas/rev24/rodriguez.htm

Rotterdam, E. (1998). Elogio de locura. Elogio de la estulticia. Bogotá: Panamericana Editorial.

Sánchez. R. (2005). Sometimiento y deformación en la obra de Luis Caballero y Lorenzo Jaramillo. En: A.M. Brigante et al. El cuerpo, fábrica del yo: producción de subjetividad en el arte de Luis Caballero y Lorenzo Jaramillo. Bogotá: Editorial Pontificia Universidad Javeriana. Pp. 201-242 
Schrodinger E. (1985). ¿Qué es la vida? el aspecto físico de la célula viva. Barcelona: Orbis.

Sennett, R. (2000). La corrosión del carácter. Las consecuencias personales del trabajo en el nuevo capitalismo. Barcelona: Editorial Anagrama.

Serrano A., J.F. (2006). Introducción. En: J.F. Serrano (ed.). Otros cuerpos, otras sexualidades (pp. 8-14). Bogotá: Instituto Pensar.

Sibilia, P. (2010). El hombre postorgánico. Cuerpo, subjetividad y tecnologías digitales. México: Fondo de Cultura Económica.

Talero, Marina. (2006). En: J.F. Serrano (ed.). Otros cuerpos, otras sexualidades. Bogotá: Instituto Pensar. Pp. 35-53.

Varela, F. (2009). La mente no está en la cabeza. Recuperado de: http://entropia-goverza.blogspot.com/2009/08/la-mente-noesta-en-la-cabeza.html

Zamorano, I. A. (2011). Zoon politikón. Cuerpo, adhesión e inscripción política. Revista digital de ensayo. Recuperado en agosto de 2011 en: http://critica.cl/ciencias-sociales/zoonpolitikon-cuerpo-adhesion-e-inscripcion-politica 